\title{
Tempers flare at hurricane meeting
}

\section{MONTEREY, CALIFORNIA}

Hurricanes may be becoming more intense because of global warming, but so is research on the topic.

Last week, meteorologists gathered in Monterey, California - the meeting was to have been held in New Orleans - to hear new evidence supporting the proposed link between rising sea surface temperatures and morepowerful hurricanes. The fresh crop of research was triggered by two papers arguing for that connection, published by coincidence during the height of the devastating Atlantic hurricane season of 2005 (K. Emanuel Nature 436, 686-688; 2005; P. Webster et al. Science $309,1844-1846 ; 2005$ ).

The effects of global warming, many say, are already in evidence. 'It's not going to happen in the future - it is actually happening now," says Greg Holland of the National Center for Atmospheric Research in Boulder, Colorado.

But not all are convinced, and there were raised voices in the hallway discussions at the American Meteorological Society meeting. At a lively panel discussion on 25 April, the moderator accepted audience questions only on written cards, and admonished the speakers not to indulge in personal attacks. This prompted Christopher Landsea, of the National Hurricane Center in Miami, to quip: "I get along personally with everyone in the field, and I want to continue that - even if they're wrong."

At issue is whether the historical record of cyclones is complete enough for accurate conclusions to be drawn about changes from past patterns. Many researchers called for the databases to be brought up to date by including modern assessments of past storms, including their intensities. It is a daunting task that, for now, is being done only for the Atlantic basin by Landsea and his colleagues.

Even given the gaps in the database, several new studies suggested that rising sea surface temperatures are having a noticeable effect on cyclones. Peter Webster of the Georgia Institute of Technology in Atlanta, co-author of one of last year's papers, presented data hinting that not only are hurricanes growing more intense over time, but that the length of the storm season has increased as well. Starting from 1950, he told the meeting, the storm season has grown longer in the Atlantic by about five days per decade, in the northeastern Pacific by eight days per decade, and in the

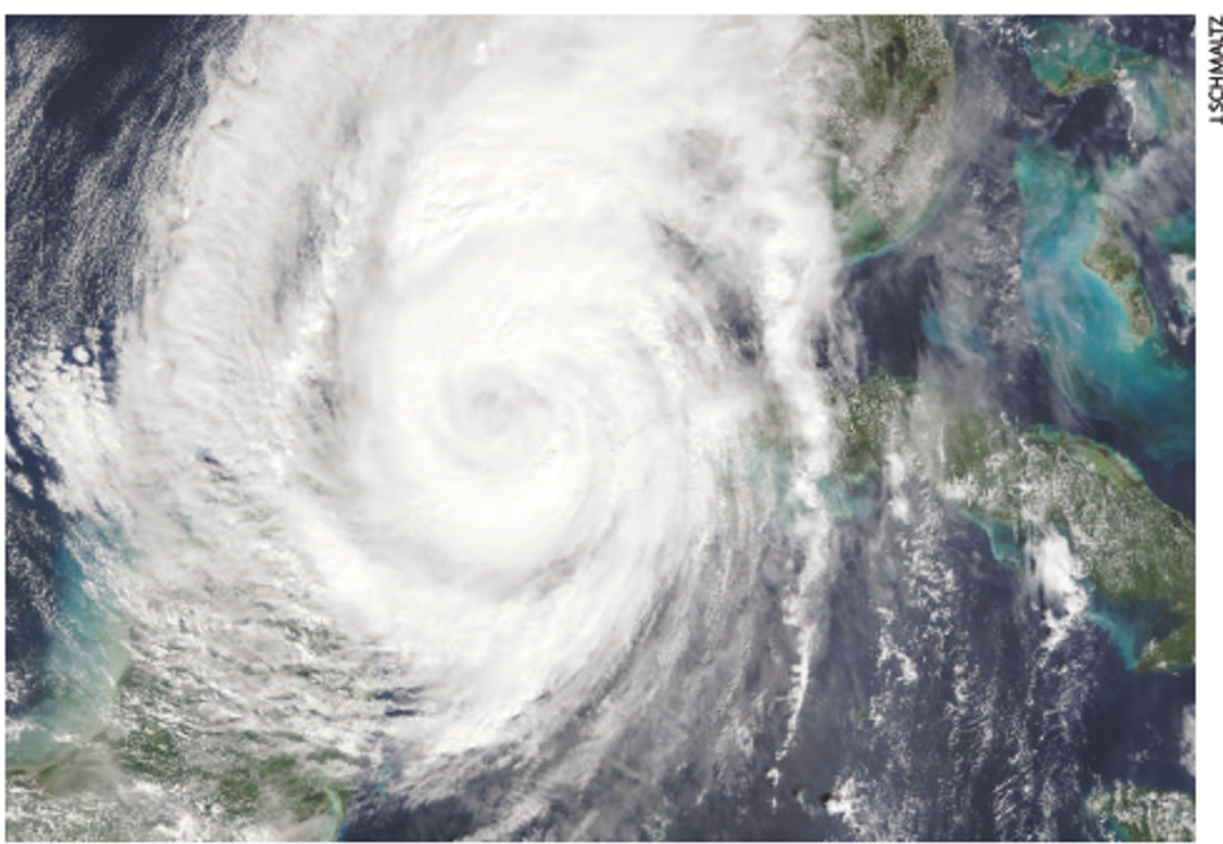

Hurricane Wilma helped to make 2005 a record hurricane year, but is global warming to blame?

northwestern Pacific by ten days per decade.

In Britain, researchers at the Benfield Hazard Research Centre in Surrey have run climate simulations suggesting that half the recent rise in hurricane activity in the North Atlantic can be explained by the observed increase in sea surface temperature in the region where these hurricanes develop. A warmer ocean would, in theory, provide more fuel for hurricanes to intensify.

And in Japan, a team has used the Earth Simulator supercomputer to run highresolution simulations of global climate, both in today's conditions and in a world warmed by higher levels of atmospheric carbon dioxide. Preliminary results suggest that, in the latter scenario, the number of tropical cyclones would drop by about $30 \%$ worldwide. But the number would rise in the Atlantic, and storm intensity would increase worldwide (K. Oouchi et al. J. Meteorol. Soc. Jap. 84, 259-276; 2006).

Kerry Emanuel, a hurricane expert at the Massachusetts Institute of Technology, and author of the other paper published last year, says that many of these models need more work before firm conclusions can be drawn. But he spent his time as a panellist demolishing another popular tenet of climate research: that a natural temperature cycle known as the
Atlantic Multi-Decadal Oscillation (AMO) controls the formation of Atlantic storms during the peak of the hurricane season. Removing the oscillation would remove one of the last arguments that hurricane patterns are driven by a natural cycle.

"There may be such a thing as an AMO, but it's not affecting the sea surface temperature in the North Atlantic in the late summer," says Emanuel.

Few of these studies have appeared in peerreviewed journals yet, and not everyone is persuaded by the conclusions. Johnny Chan, of the City University of Hong Kong, presented data suggesting that in the northwestern Pacific, numbers of typhoons do not track with rising sea surface temperatures.

One major critic is William Gray, a longtime forecaster at Colorado State University, Fort Collins, whose climate theories have been criticized by many researchers. He continued to insist that hurricanes are driven more by natural patterns of ocean circulation than by human-induced global warming. ${ }^{\alpha} \mathrm{I}$ don't care what anyone says - in the end the data will prove this to be true, ${ }^{\text {, he says. }}$ "Why try to read all these demonic influences into the system?"

Forecasters, including Gray, are predicting that a busier-than-usual Atlantic hurricane season will start on 1 June.

Alexandra Witze 